\title{
OP87
}

\section{VISUAL COMFORT EVALUATION METHOD AND PREDICTION MODEL RELATING TO DISCOMFORT GLARE: A MOCK-UP STUDY OF LUMINOUS ENVIRONMENT IN AIRPLANE COCKPIT}

\author{
Chunze WU et al.
}

DOI 10.25039/x46.2019.OP87

from

CIE x046:2019

\author{
Proceedings \\ of the \\ 29th CIE SESSION
}

Washington D.C., USA, June $14-22,2019$

(DOI $10.25039 / \times 46.2019)$

The paper has been presented at the 29th CIE Session, Washington D.C., USA, June 14-22, 2019. It has not been peer-reviewed by CIE.

(C) CIE 2019

All rights reserved. Unless otherwise specified, no part of this publication may be reproduced or utilized in any form or by any means, electronic or mechanical, including photocopying and microfilm, without permission in writing from CIE Central Bureau at the address below. Any mention of organizations or products does not imply endorsement by the CIE.

This paper is made available open access for individual use. However, in all other cases all rights are reserved unless explicit permission is sought from and given by the CIE.

CIE Central Bureau

Babenbergerstrasse 9

A-1010 Vienna

Austria

Tel.: +4317143187

e-mail: ciecb@cie.co.at

www.cie.co.at 


\title{
VISUAL COMFORT EVALUATION METHOD AND PREDICTION MODEL RELATING TO DISCOMFORT GLARE: A MOCK-UP STUDY OF LUMINOUS ENVIRONMENT IN AIRPLANE COCKPIT
}

\author{
Chunze WU ${ }^{1}$, Xiaofeng YUAN ${ }^{1}$, Jian $\mathbf{L I}^{2}$, Biao YANG ${ }^{2}$ \\ ${ }^{1}$ Shanghai Aircraft Design and Research Institute, Shanghai, CHINA \\ ${ }^{2}$ School of Architecture, Harbin Institute of Technology (Shenzhen), Shenzhen, Guangdong, \\ CHINA \\ chrislee@hit.edu.cn, yangbiao@hit.edu.cn
}

DOI $10.25039 / \times 46.2019 .0 P 87$

\begin{abstract}
Glare is a key factor that influencing the visual performance in light conditions of airplane cockpit, and intensity and layout of glare sources in cockpit are extraordinarily complex. This study investigates the relationship between complex glare sources and discomfort glare evaluations of luminous environment in airplane cockpit. Different glare indices are proposed to predict the level of discomfort glare in the cockpit environment with non-uniform glare sources and irregular shape glare sources. The result shows the DGP can predict the visual comfort evaluation better than DGI and UGR in complex luminous environments.
\end{abstract}

Keywords: Discomfort Glare, DGP, Airplane Cockpit,

\section{Introduction}

The visual comfort property of airplane cockpit is of immediate impact on pilot. It could cause the pilot visual fatigue and misoperation, and be bad for the health of the pilot and safe driving ( $\mathrm{Li}$, et al., 2013). Therefore, the cockpit luminous environment has a significant status of airplane visual ergonomics design for visual performance, which is related to brightness range, choice of colour, auxiliary lighting, glare control etc. In this context, the authors define visual comfort as the absence of discomfort such as glare, insufficient visual contrast or the presence of visible direct sunlight.

Glare is the condition of vision in which there is discomfort or a reduction in the ability to see details or objects, caused by an unsuitable distribution or range of luminance, or by extreme contrasts (CIE, 1987). It can be subdivided in three kinds. Disability glare is defined as a type of glare which impairs the vision. It is caused by scattering of light inside the eye because of the imperfect transparency of the optical components of the eye, and to a lesser extent by diffuse light passing through the scleral wall or the Iris (CIE, 2002). Discomfort glare is the glare that causes discomfort without necessarily impairing the vision of objects. Veiling glare is defined as the reflection-associated contrast-reduction due to which, the contrast of the visual target falls below the required value, causing difficulty in visibility or readability of the target (Moghbel, 2012).

The human eye can encounter a wide range of luminances, from $0.000001 \mathrm{~cd} / \mathrm{m}^{2}$ (very dark night) to $10000 \mathrm{~cd} / \mathrm{m}^{2}$ (sunlit beach) (Wördenweber et al., 2007). The state of adaptation of the human eye dictates the spectral sensitivity because at different luminances different photoreceptors (rods and cones) are active. There are three defined states of the spectral sensitivity of the human eye, which are photopic vision, scotopic vision and mesopic vision (Boyce, 2009). In the luminous environment such as airplane cockpit, the human eye acts adaptively and the visual perception changes accordingly.

In order to fully understand the relationship between the complex luminous environment and human visual discomfort perception, the authors created a wide range of luminous environments, using the strong lamp to simulate the outdoor sunlight and a real-size demo mock-up for indoor illumination, which may cause a mixed effect of discomfort glare and veiling glare. The goal of 
the study is to get a reliable and repeatable evaluation method as the prediction model for discomfort glare in luminous environments.

\section{Discomfort Glare Evaluation}

Discomfort Glare Models such as UGR (Wienold \& Christoffersen, 2006) and DGI (Nazzal, 2005) focus on the ratio between the source luminance and the background luminance, but the technical specifications of the source (number of sources, type, dimensions, position in the field of view, etc.) are accounted for the same way in all the models (Anthierens et al., 2008).

The CIE recommended Unified Glare Rating (UGR) is the most widely applied because it includes the best features of available models and performed well in predicting conventional sources with uniform luminance (CIE, 1995).

DGI (Daylight Glare Index), is based on an analytic relation, the Cornell formula, that was developed in order to define discomfort glare from large artificial light sources (Hopkinson \& Bradley, 1960). It is a version of the BGI (Building Research Station Glare Index), modified on the base of results of the experiments with large artificial light sources (Luckiesh \& Guth, 1949). For sources with non-uniform levels of luminance, DGI presents some limits and some difficulties.

The DGP (Daylight Glare Probability) allows to obtain a discomfort glare evaluation in accordance with the results obtained through perceptive tests, by taking into consideration the whole visual field as well as the visual task. Such evaluation has been carried out through measurement obtained by means of CCD - camera technique on real conditions. The metric is utilized to represent discomfort glare because it accounts for contrast and brightness whereas other glare metrics only account for contrast (Wienold \& Christoffersen, 2006). Jakubiec and Reinhart (2012) showed that DGP is the most robust of existing discomfort glare metrics and the least likely to give false positives.

Most models are rendered as a logarithmic function in order to highlight the obvious fact that human perception is not a linear phenomenon. Many experimental studies reveal that the eye reacts to glare in a predictable way, given the distribution of rods and cones within the retina. The closer one gets to the fovea, the higher the density of sensitive elements gets (Provis et al., 2013). Even if the function of the eye can be considered as a sensor, the fact should not be ignored that human perception is subjective and relates to the individual's behaviour and environment. Based on statistical studies, several models are synthesized as a formal mathematical formula that ignores the uncertainties and inaccuracies of parameters (Wonwoo \& Yasuko 2005).

The analysis of human sight should consider the whole chain of perception, from as early as the signal acquisition through the sensor (eye), to its final interpretation (brain). Nevertheless, this whole chain is quite arduous to understand and model, which is why existing models are structured from divergent assumptions, thus sometimes not in complete agreement with one another (Anthierens el al., 2008). Researchers from different fields have given attention to physiological as well as psychological responses to visual situations exhibiting discomfort glare. Bargary et al. (2015) studied the mechanism or physiological underpinnings that lead to discomfort glare. They elucidated some of the underlying mechanisms by controlling the amount of light reaching the retina and by varying the photometric properties of the glare source. They predicted the visual data using a two-stage model based on saturation of photoreceptors followed by summation of an edge response signal that defines the edges of the glare-source. Another psycho-physical model has recently been proposed by Scheir et al (2016). to evaluate visual discomfort. Safdar et al. (2018) used the neural computations of the human visual system to model neural responses to glare based on the spatial distribution of luminance, which refers to a model they called neural response-based glare model (NRGM).

\section{Method}

In the experiment, three variables were manipulated to simulate different lighting conditions for the daylight/night flight mode separately. Using the luminance adjustment of three different lighting parts of the cockpit, primary flight display (brightness range: $0 \%, 25 \%, 50 \%, 75 \%, 100 \%$ ), 
light plate(brightness range: $0 \%, 50 \%, 100 \%$ ), flood light (brightness range: $0 \%, 50 \%, 100 \%$ ) for the night flight mode, and strong lamp simulated as sunlight (2000-15000 lux, 7 logarithmic grades), primary flight display (brightness range: 0\%-50\%-100\%), and thunderstorm light (ON/OFF) for the daylight flight mode, 87 different light conditions (45 of them for the night flight mode, the rest for the daylight flight mode) were presented in a real-size demo mock-up experimental set-up. All confounding variables are well-controlled.
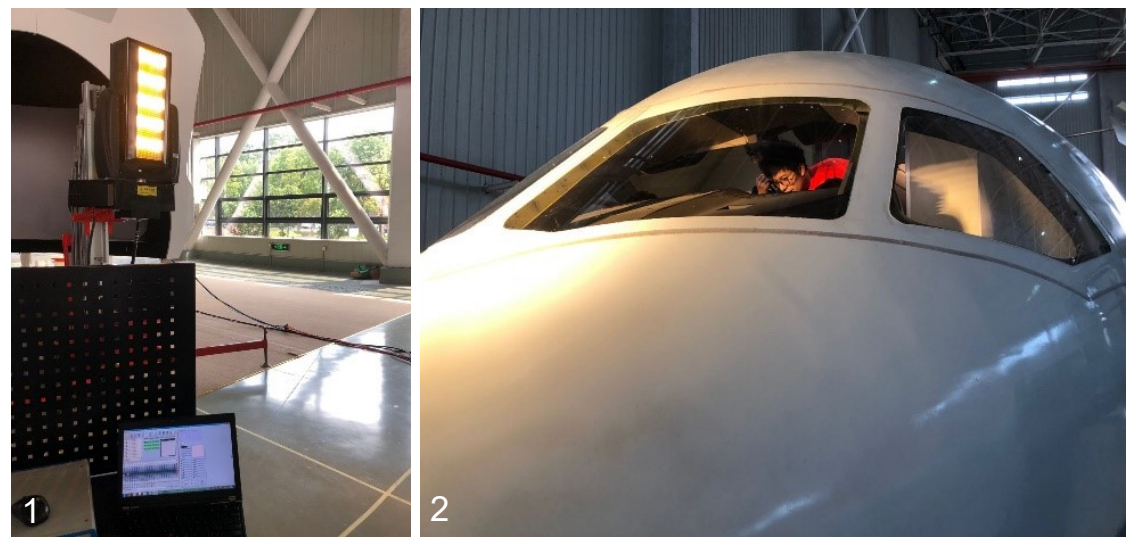

Figure 1 - the lamp and the cockpit domo mock-up

20 Participants were requested to judge the perceived discomfort glare of three main parts of cockpit which include primary flight display, overhead panel and control pedestal in these light conditions using the nine-level comfort rating scale in both flight mode respectively. In the daylight flight mode, during the pre-training session participants were shown the two extreme conditions of discomfort which are classed as follows: a grade ' 1 ' indicating the most comfortable sensation and the opposite extreme - grade ' 9 ' in which the participant have the most uncomfortable sensation. All conditions were presented randomly and each stay still above 1 minute for participant's light adaptation.
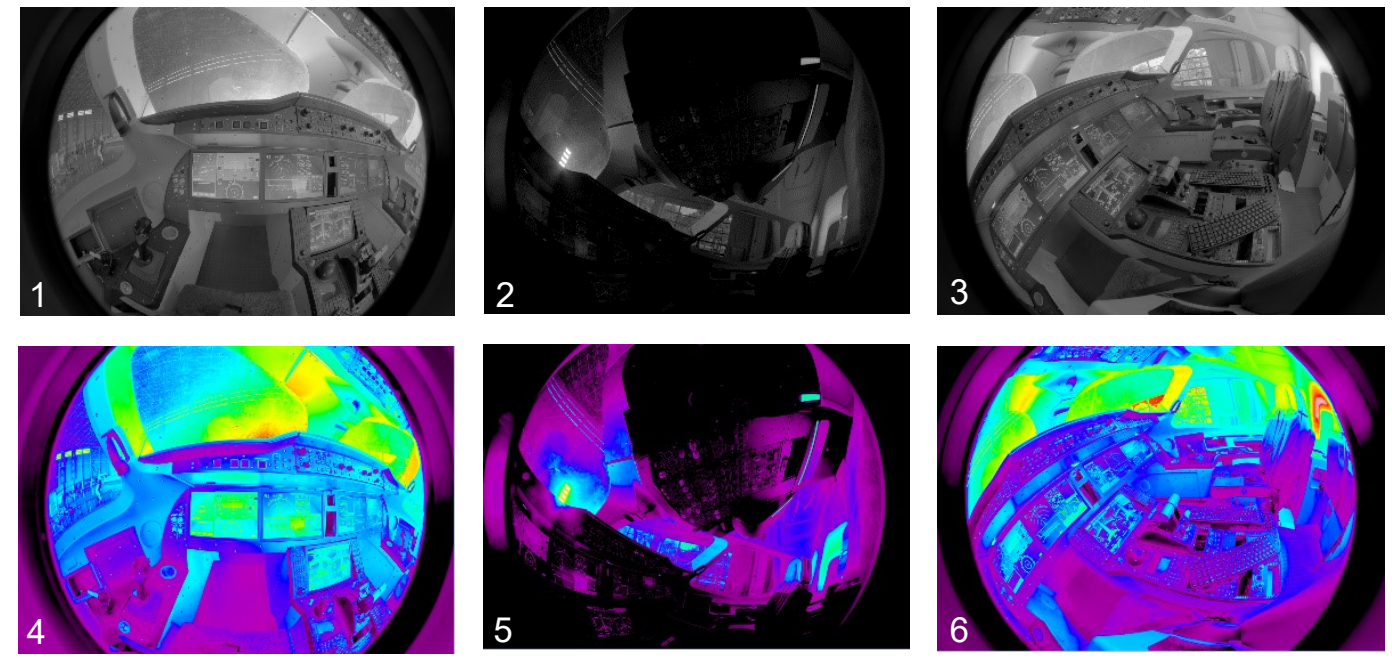

Figure 2 - the luminance images and false colour images for the daylight flight mode (from left to right: primary flight display view, overhead panel view and control pedestal view)

For each condition, luminance measurement based on CCD (Charge-Coupled Device) camera's High Dynamic Range (HDR) luminance mapping technology was processed. Five parameters of the glare sources, include source luminance, background luminance, position index, solid angle of source, and the vertical illuminance were selected to compute different discomfort glare indexes include UGR, DGI, and DGP. The NGRM model was also computed, the detailed computation procedure was based on Safdar's work (Safdar et al., 2018). The correlation analysis was implemented to find the relationship between different glare models and the 1-9 
comfort ratings results. The correlation coefficient of each glare model was measured as the criterion for model evaluation.

\section{Result and Discussion}

A repeated-measures AVONA on the data demonstrated that the comfort ratings for all view directions increase with decreasing flood light luminance $(F=36.563, \mathrm{df}=6, p<0.001)$ and light plate luminance $(F=22.883, d f=6, p<0.001)$ in the night flight mode. As for the primary flight display, with the increase of luminance, the comfort rating first decreases and then increases like a ' $U$ '-shape curve $(F=2.135, d f=12, p=0.012)$. In the daylight flight mode, increase of the luminance of strong lamp, increase the comfort rating for each view directions $(F=27.535, \mathrm{df}=18$, $\mathrm{p}<0.001)$. The comfort rating of overhead panel increases with the decreasing luminance of primary flight display $(F=5.730, d f=2, p=0.003)$. The thunderstorm light decreases the comfort rating of control pedestal $(F=10.448, d f=3, p<0.001)$.

The correlation analysis results between different glare models and the comfort ratings are descripted in Table 1 below. It is apparent that current glare indices based on UGR or DGI is failed to reflect these trends and variations of discomfort glare perception. And DGP can predicts the comfort level better than UGR and DGI in the daylight flight mode, but it becomes worse in the night flight mode. The optimal NRGM is strongly correlated to the DGP in the daylight flight mode, but the optimal $k$ value varies between different viewpoint, which could suggest different visual process are involved in the glare perception from different views. And the further investigation is needed.

Table 1 - correlation coefficient between each model and comfort ratings

\begin{tabular}{|c|c|c|c|c|c|c|c|c|c|c|}
\hline \multirow[b]{2}{*}{$\begin{array}{l}\text { Luminous } \\
\text { Environment }\end{array}$} & \multirow{2}{*}{$\begin{array}{l}\text { Evaluation } \\
\text { Viewpoint }\end{array}$} & \multirow{2}{*}{$\begin{array}{l}\text { Background } \\
\text { Luminance }\end{array}$} & \multirow[b]{2}{*}{ Illuminance } & \multirow[b]{2}{*}{ UGR } & \multirow[b]{2}{*}{ DGI } & \multirow[b]{2}{*}{ DGP } & \multicolumn{4}{|c|}{ NRGM } \\
\hline & & & & & & & $k=1$ & $\mathrm{k}=3$ & $k=5$ & $k=7$ \\
\hline \multirow[t]{3}{*}{$\begin{array}{l}\text { Night Flight } \\
\text { Mode }\end{array}$} & $\begin{array}{c}\text { Primary } \\
\text { Flight } \\
\text { Display }\end{array}$ & -0.43 & -0.32 & 0.19 & $\underline{0.21}$ & -0.23 & -0.42 & 0.05 & 0.14 & 0.16 \\
\hline & $\begin{array}{l}\text { Overhead } \\
\text { Panel }\end{array}$ & 0.08 & $\underline{0.09}$ & 0.01 & 0.00 & -0.23 & $\underline{0.05}$ & 0.04 & 0.04 & 0.04 \\
\hline & $\begin{array}{l}\text { Control } \\
\text { Pedestal }\end{array}$ & 0.00 & $\underline{0.03}$ & -0.12 & -0.12 & 0.01 & -0.25 & -0.09 & -0.02 & $\underline{0.03}$ \\
\hline \multirow[t]{3}{*}{$\begin{array}{l}\text { Daylight } \\
\text { Flight Mode }\end{array}$} & $\begin{array}{c}\text { Primary } \\
\text { Flight } \\
\text { Display }\end{array}$ & $\underline{0.43}$ & 0.39 & -0.42 & -0.42 & $\underline{0.39}$ & 0.05 & $\underline{0.39}$ & 0.36 & 0.31 \\
\hline & $\begin{array}{l}\text { Overhead } \\
\text { Panel }\end{array}$ & $\underline{0.38}$ & 0.34 & 0.24 & 0.23 & 0.34 & $\underline{0.35}$ & -0.16 & -0.16 & -0.16 \\
\hline & $\begin{array}{l}\text { Control } \\
\text { Pedestal }\end{array}$ & 0.26 & 0.28 & -0.20 & -0.26 & $\underline{0.28}$ & $\underline{0.28}$ & 0.14 & 0.16 & 0.17 \\
\hline
\end{tabular}

Note: the optimal results for the correlation coefficients are underlined and bolded.

\section{Conclusion}

The study fills the gap in estimating discomfort glare of complex lighting and clarified similarities of and differences in discomfort glare between airplane cockpit lighting and traditional light sources. DGP is a better than UGR/DGI for modelling the discomfort glare in the complex luminous environment, but the model is still far from good. The NRGM model has a strong correlation to DGP, and has the potential to reflect the adaptive visual process and extend the glare evaluation model in a more general environment. Therefore, a new principle would be 
necessary to evaluate the glare perception in the circumstances different from simple luminous environment like airplane cockpit.

\section{References}

ANTHIERENS, C., LECLERCQ, M., BIDEAUX, E., \& FLAMBARD, L..2008. A smart sensor to evaluate visual comfort of daylight into buildings. International Journal of Optomechatronics, 2(4), 413-434.

BARGARY, G., JIA, Y., \& BARBUR, J. L. 2015. Mechanisms for discomfort glare in central vision. Investigative ophthalmology \& visual science, 56(1), 464-471.

BOYCE, P. R. 2008. Lighting for driving: roads, vehicles, signs, and signals. CRC Press.

CIE.1987. International Lighting Vocabulary. Geneva: Bureau Central de la Commission Electrotechnique Internationale.

CIE. 1995. Discomfort Glare in Interior Lighting. Technical report 117. CIE.

CIE. 2002. CIE Collection on Glare, Commission Internationale de l'Éclairage (CIE), Austria

HOPKINSON, R.G., BRADLEY R.C. 1960. A study of glare from very large sources, Illuminating Engineering, 55, No. 5, pp. 288-294

JAKUBIEC, J. A., \& REINHART, C. F. 2012. The 'adaptive zone'-A concept for assessing discomfort glare throughout daylit spaces. Lighting Research \& Technology, 44(2), 149170.

LUCKIESH, M., \& GUTH, S. K. 1949. Brightness in visual field at borderline between comfort and discomfort (BCD). Illuminating engineering, 44(11), 650-670.

MOGHBEL, N. 2012. New model for VDT associated visual comfort in office spaces (Doctoral dissertation, Verlag nicht ermittelbar).

NAZZAL, A. 2005. A new evaluation method for daylight discomfort glare. International Journal of Industrial Ergonomics 35(4):295-306.

PROVIS, J. M., DUBIS, A. M., MADDESS, T., \& CARROLL, J. 2013. Adaptation of the central retina for high acuity vision: cones, the fovea and the avascular zone. Progress in retinal and eye research, 35, 63-81.

SAFDAR, M., LUO, M. R., MUGHAL, M. F., KUAI, S., YANG, Y., FU, L., \& ZHU, X. 2018. A neural response-based model to predict discomfort glare from luminance image. Lighting Research \& Technology, 50(3), 416-428.

SCHEIR, G. H., DONNERS, M., GEERDINCK, L. M., VISSENBERG, M. C. J. M., HANSELAER, P., \& RYCKAERT, W. R. 2018. A psychophysical model for visual discomfort based on receptive fields. Lighting Research \& Technology, 50(2), 205-217.

WIENOLD, J., \& CHRISTOFFERSEN, J. 2006. Evaluation methods and development of a new glare prediction model for daylight environments with the use of CCD cameras. Energy and buildings, 38(7), 743-757.

WONWOO, K., \& YASUKO, K. 2005. Glare constant Gw for the evaluation of discomfort from windows. Solar energy, 78(1), 105-111.

WÖRDENWEBER, B., WALLASCHEK, J., BOYCE, P., \& HOFFMAN, D. 2007. Automotive Lighting and Human Vision: Springer. 